\title{
Review of "Parasitoids"
}

\author{
Carlos Henrique Marchiori
}

1 Ins tituto Federal Goiano

Insect parasitoids have an immature life stage that develops on or within a single insect host, ultimately killing the host, hence the value of parasitoids as natural enemies. Adult parasitoids are free-living and may be predaceous. Parasitoids are often called parasites, but the term parasitoid is more technically correct. Most beneficial insect parasitoids are wasps or flies, although some rove beetles (see Predators) and other insects may have life stages that are

parasitoids. https://biocontrol.entomology.cornell.edu/parasitoids.php.

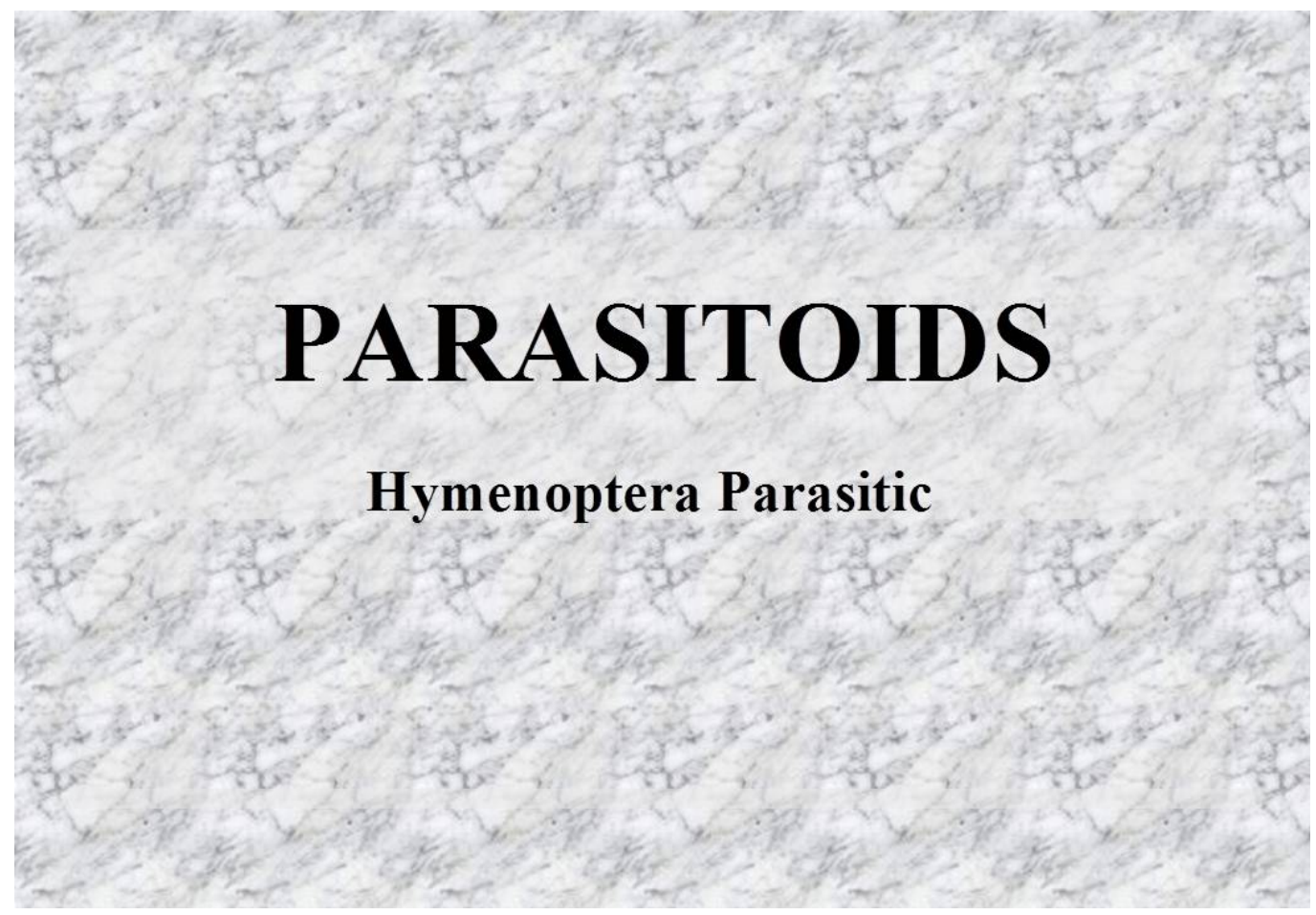

Caption 


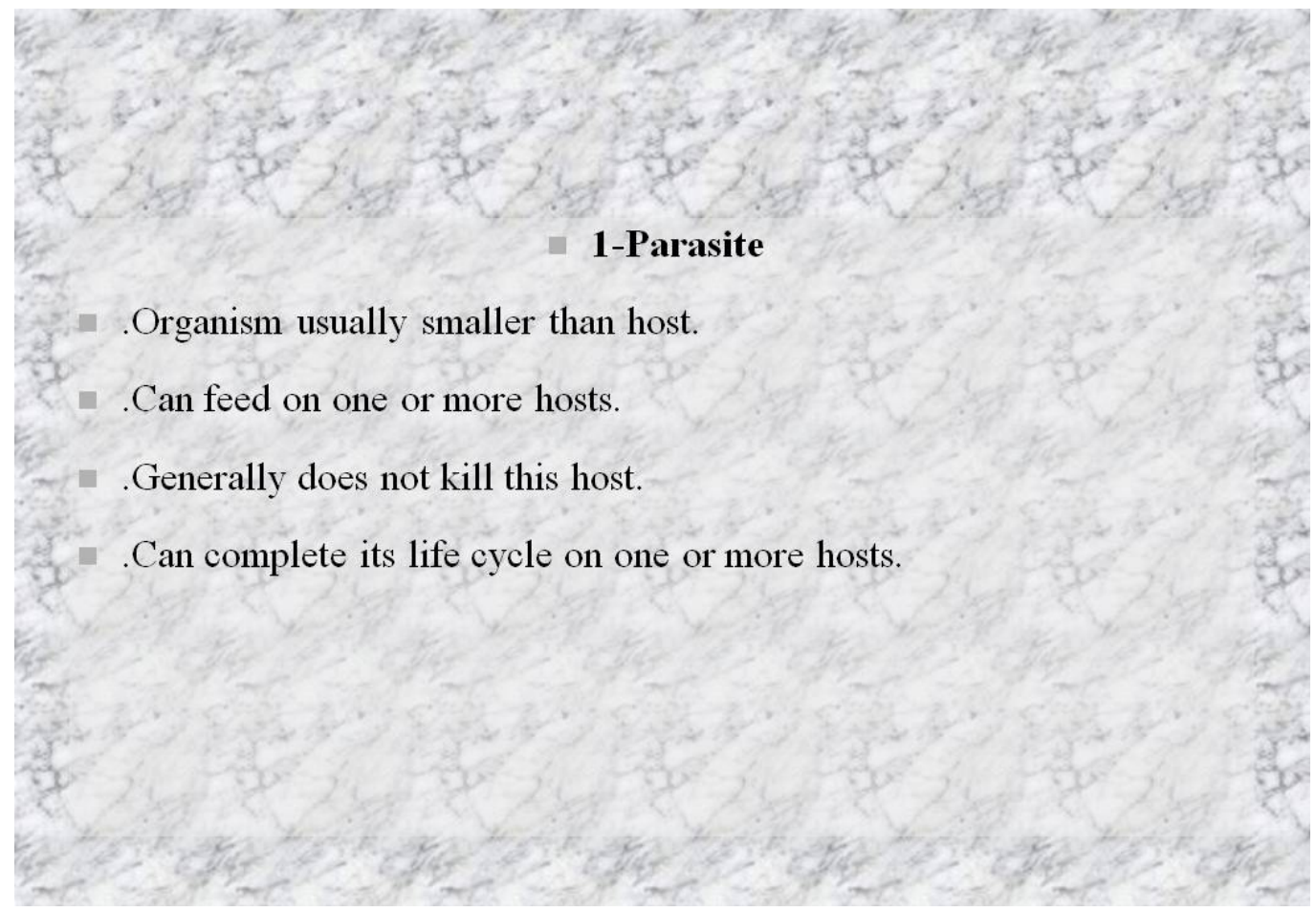

Caption

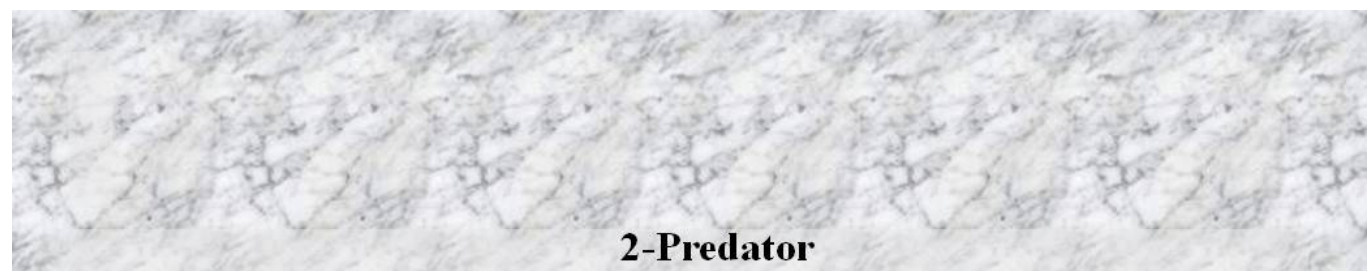

.Free-living organism throughout the cycle.

.Development at the expense of several individuals - prey.

.Adult mobile immature stages and stages generally larger than those of prey.

.Larvae and adults (male and female) are predators.

.Requires more than one individual to complete development. 


\section{3-Parasitoid (Reuter, 1913).}

.Generally do not immediately kill their host, however, in the end, the host is killed.

The immature always kill the host.

.Only the female looks for the host.

.Different parasitoid species may attack different stages.

of the host life cycle (larva-nymph-pupa and adult).

.Your eggs or larvae are usually placed on, in or near the hosts.

.Adults are free living.

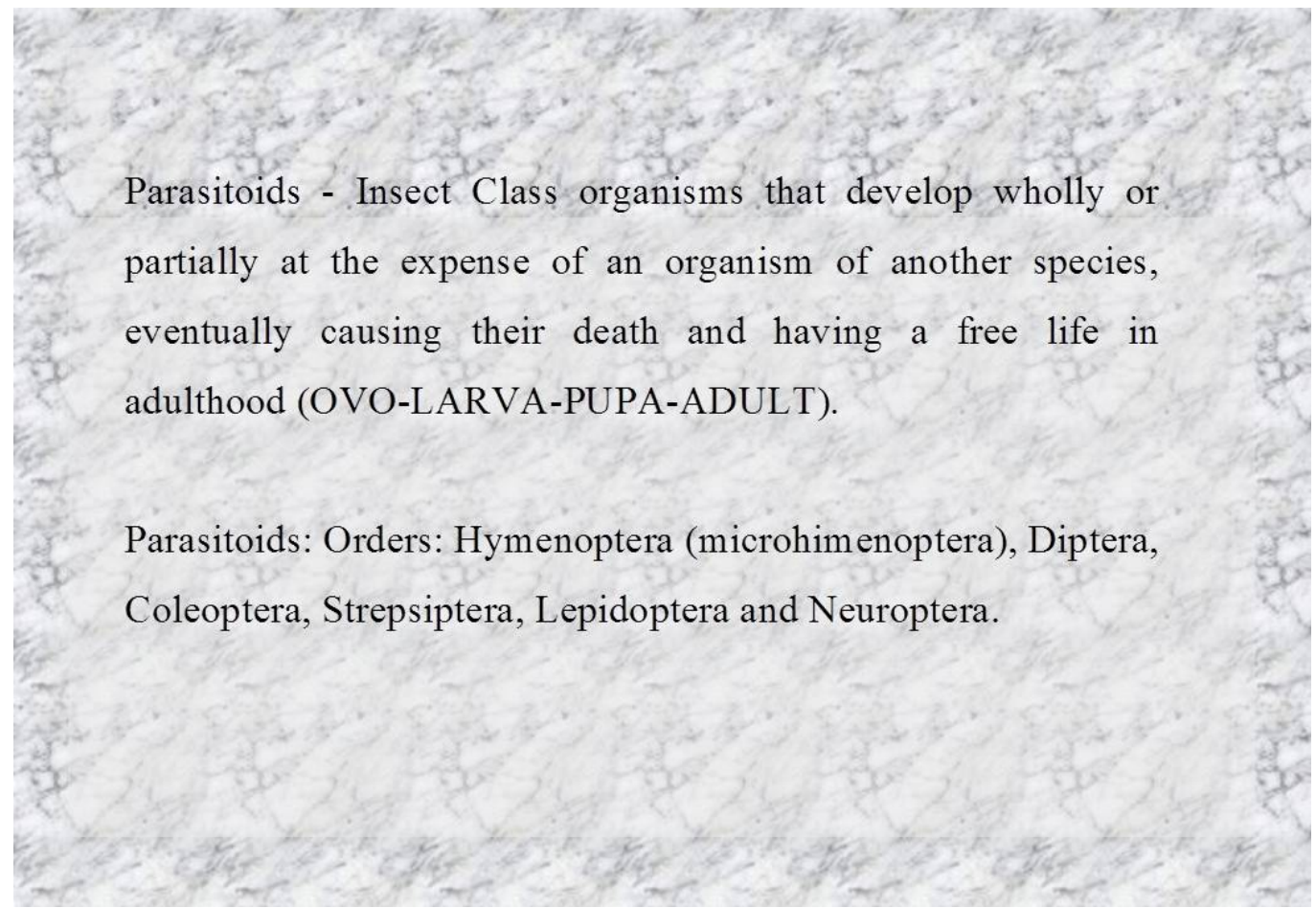


1-Egg Parasitoid - penetrates the egg and emerges from the egg or larva.

2-Larva parasitoid - penetrates the larva and emerges from the larva or pupa.

3-Pupa parasitoid-enters the pupa and emerges from the pupa.

4-Adult parasitoid - penetrates adult and emerges from adult.

Caption
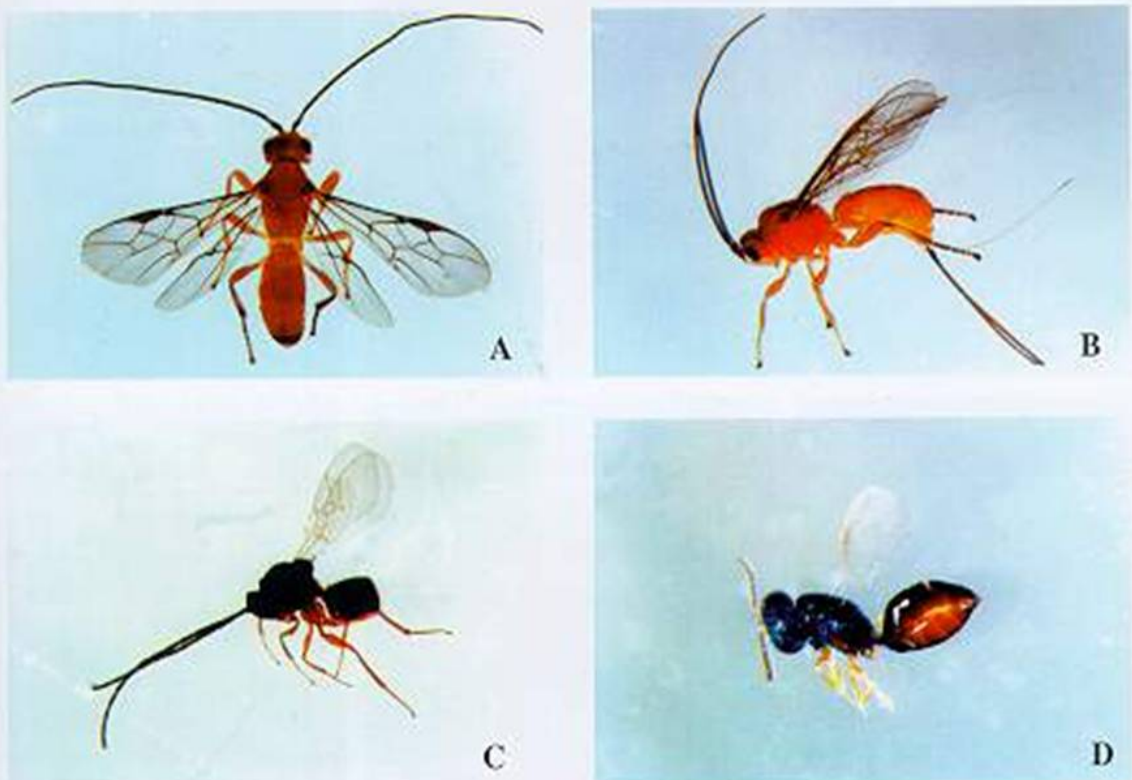

Figura 15. Representantes (adeltos) das familias mais comuns de parasitoides de moceas-das-frutas no Brasil. A-B. Bracenidae (A, macho; B, fenea); C. Figitidae; D. Pterumalidac. 


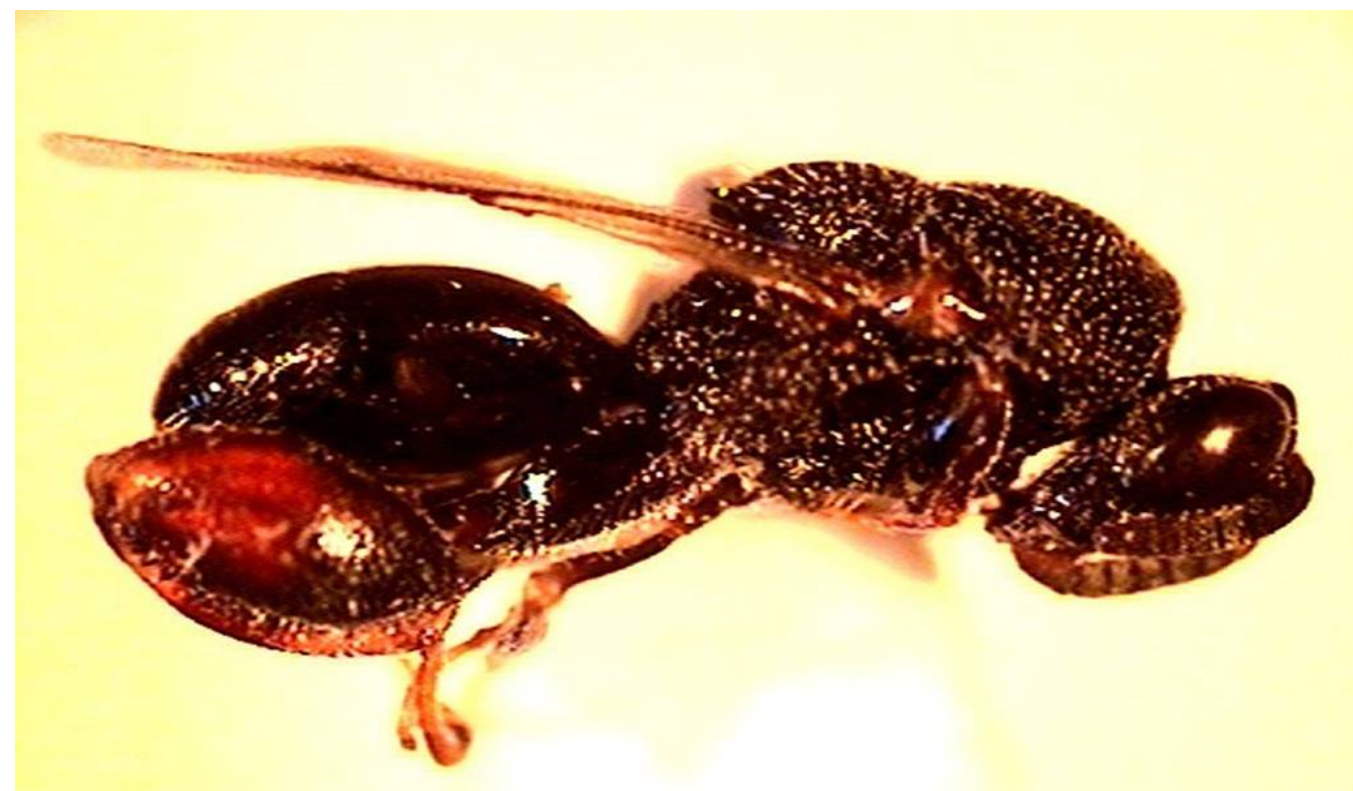

Brachymeria podagrica (Fabricius) (Hymenoptera: Chalcididae)

Caption

Ovruski 1994b; Fergusson 1995).

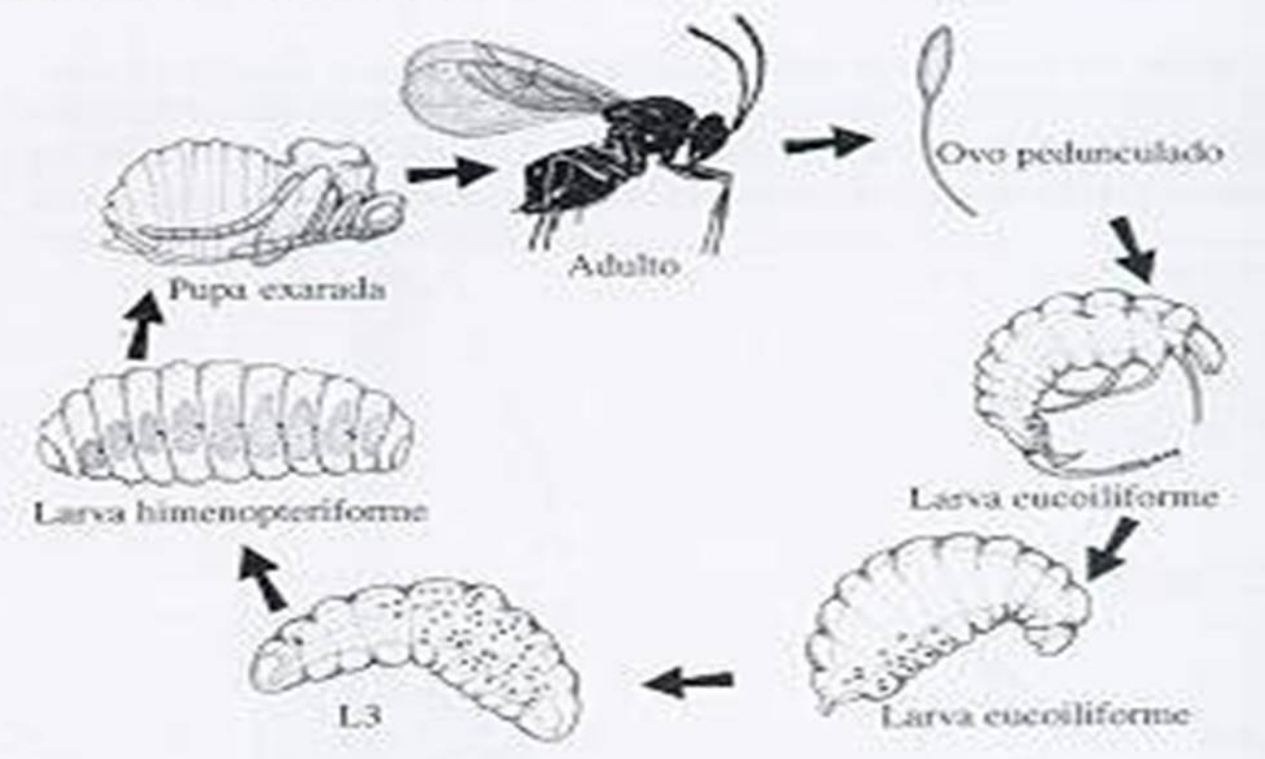

Figura 16.7. Ciclo biológico dos Eucuilinac (Agavaspis pelleranon) (bsseaclo de Owraski, 1994b)- 

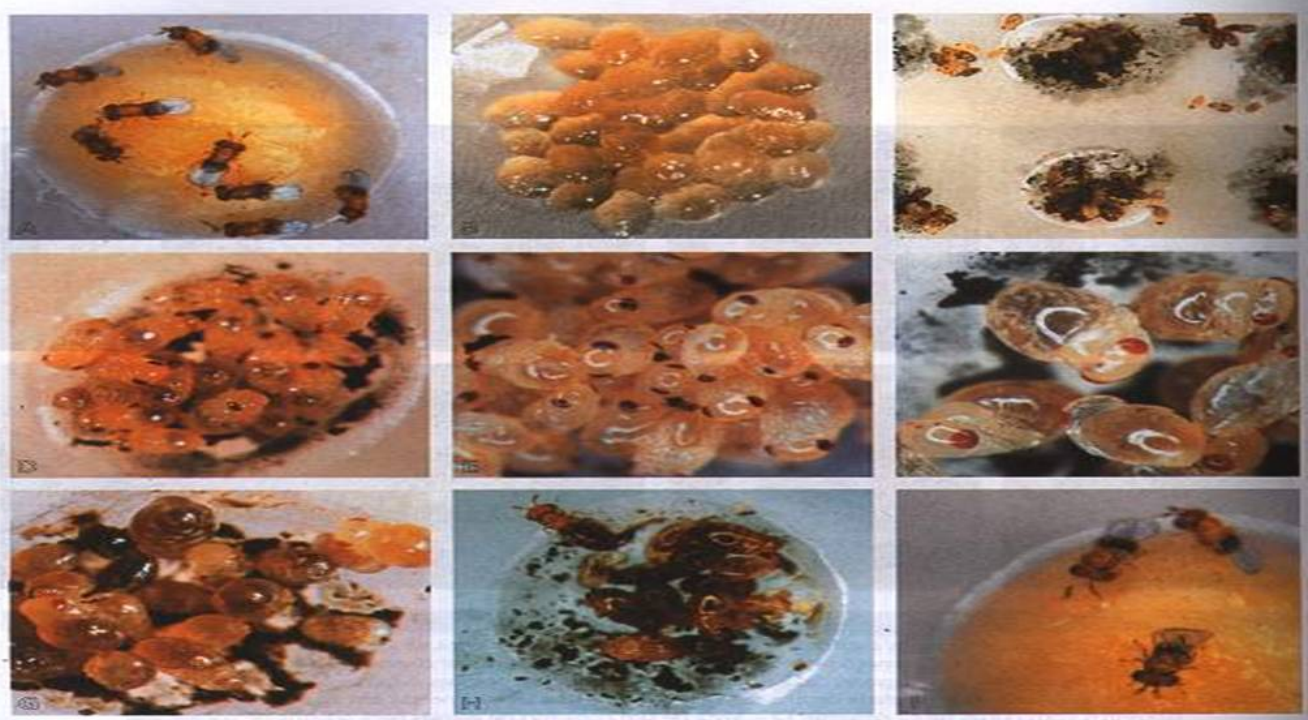

Sequência de produçäo in vitro de Trichogrommo (A-1) desde o parasitismo em ovos artificiais, larvas em diversos estapios de

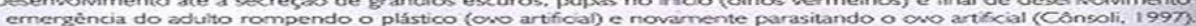
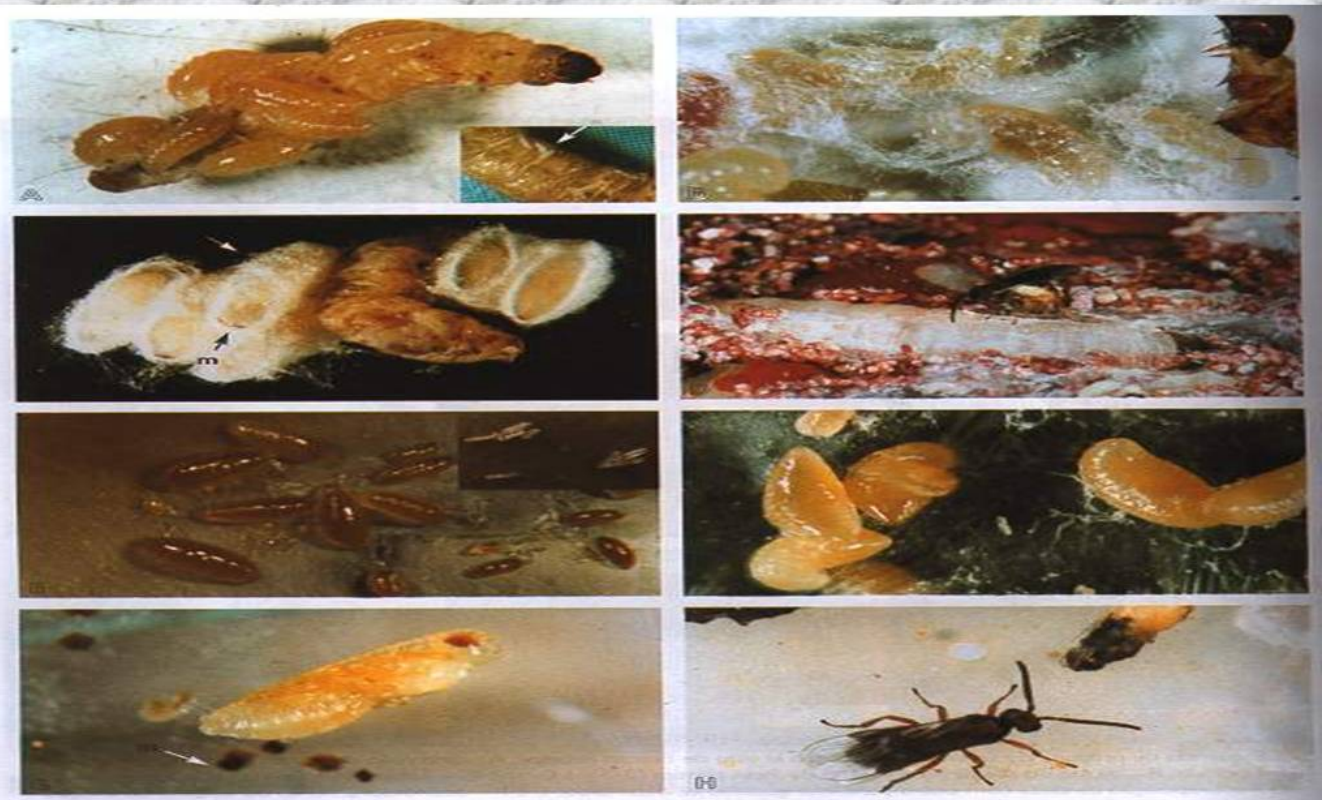

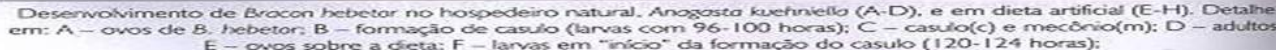
G-Pupas setas

Caption 

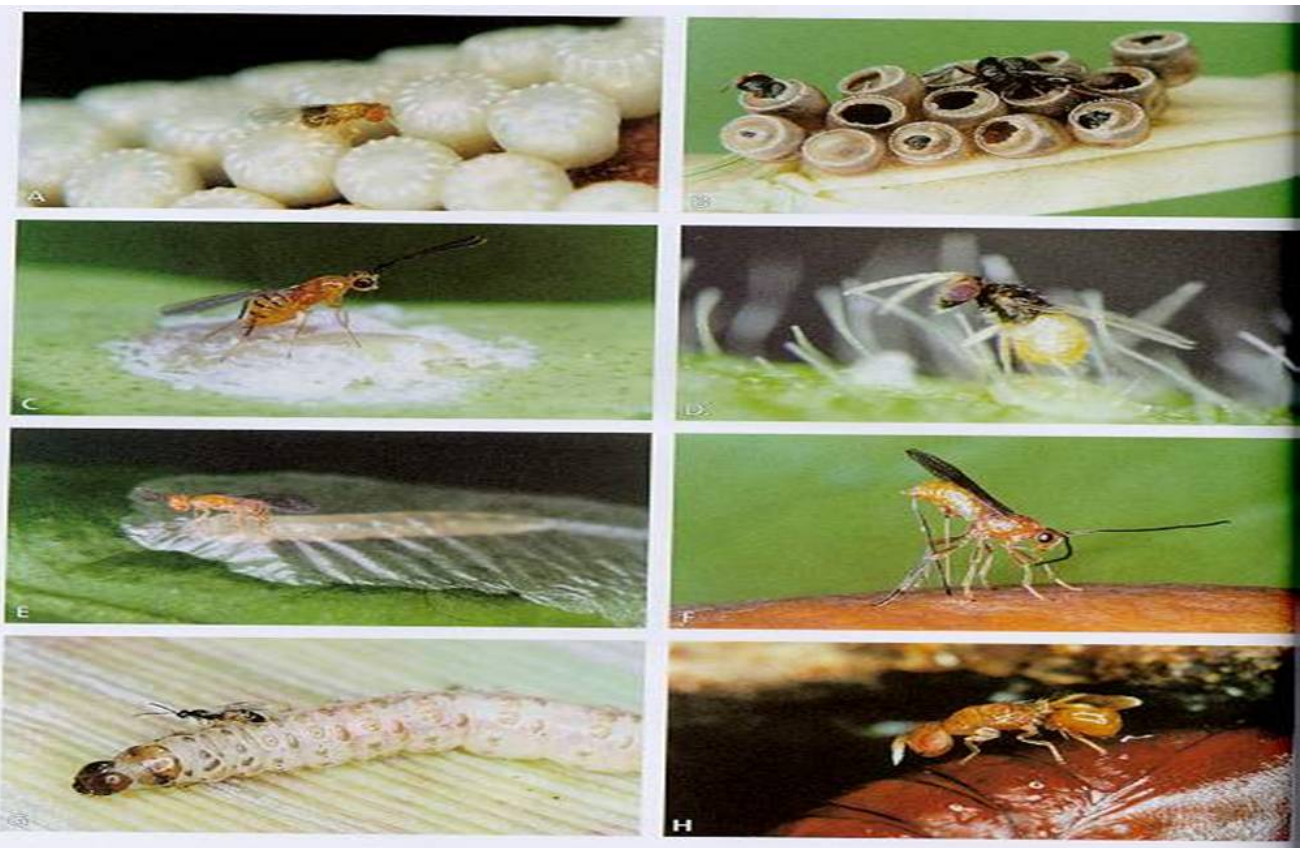

FIGURA 7.4

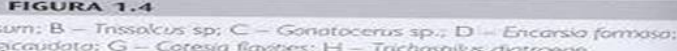

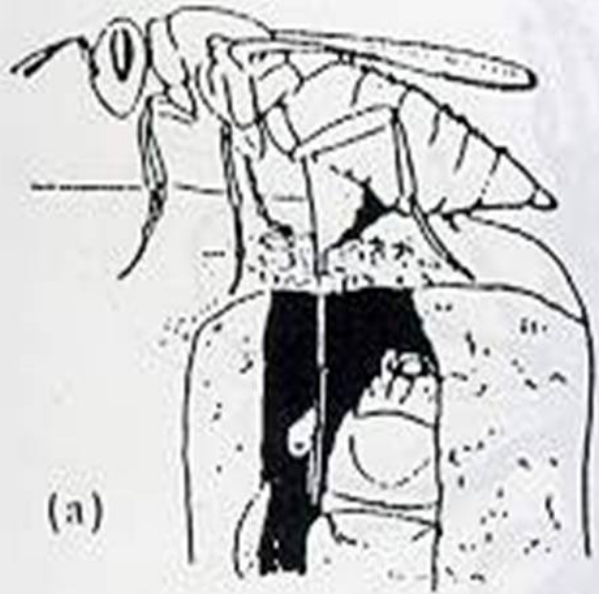

(b)

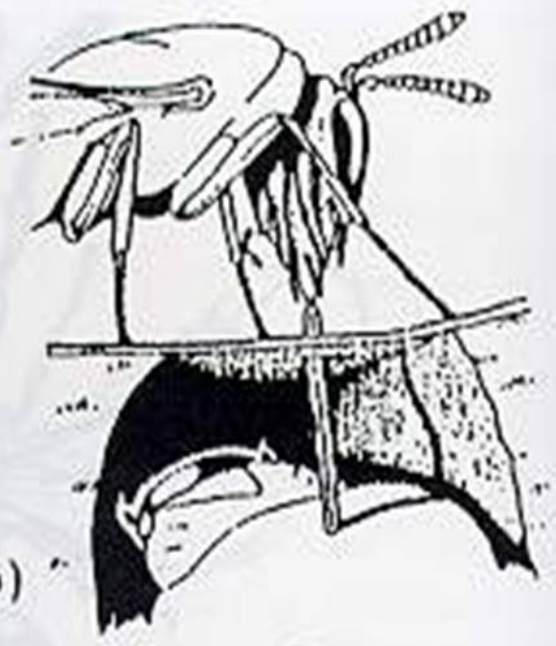

Figura 52. Fèmea de Habroxtus cerealellae (Chalcidoidea, Preromalidae): (a) ovipositando na lagarta da traça dos cereais; (b) alimentantorse pelo tubo construido com seu ovipositor (Fulton, 1933). 


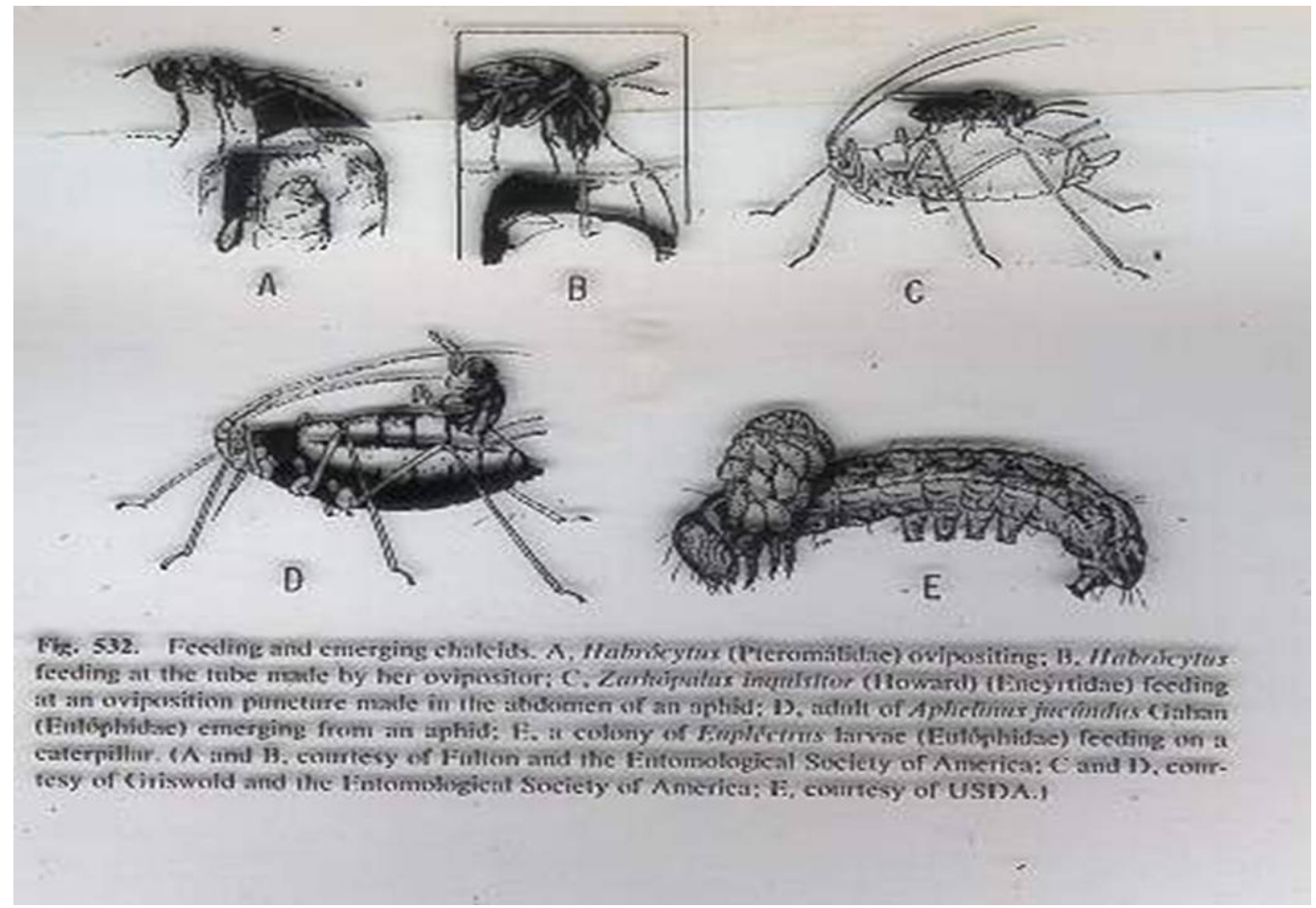

Caption

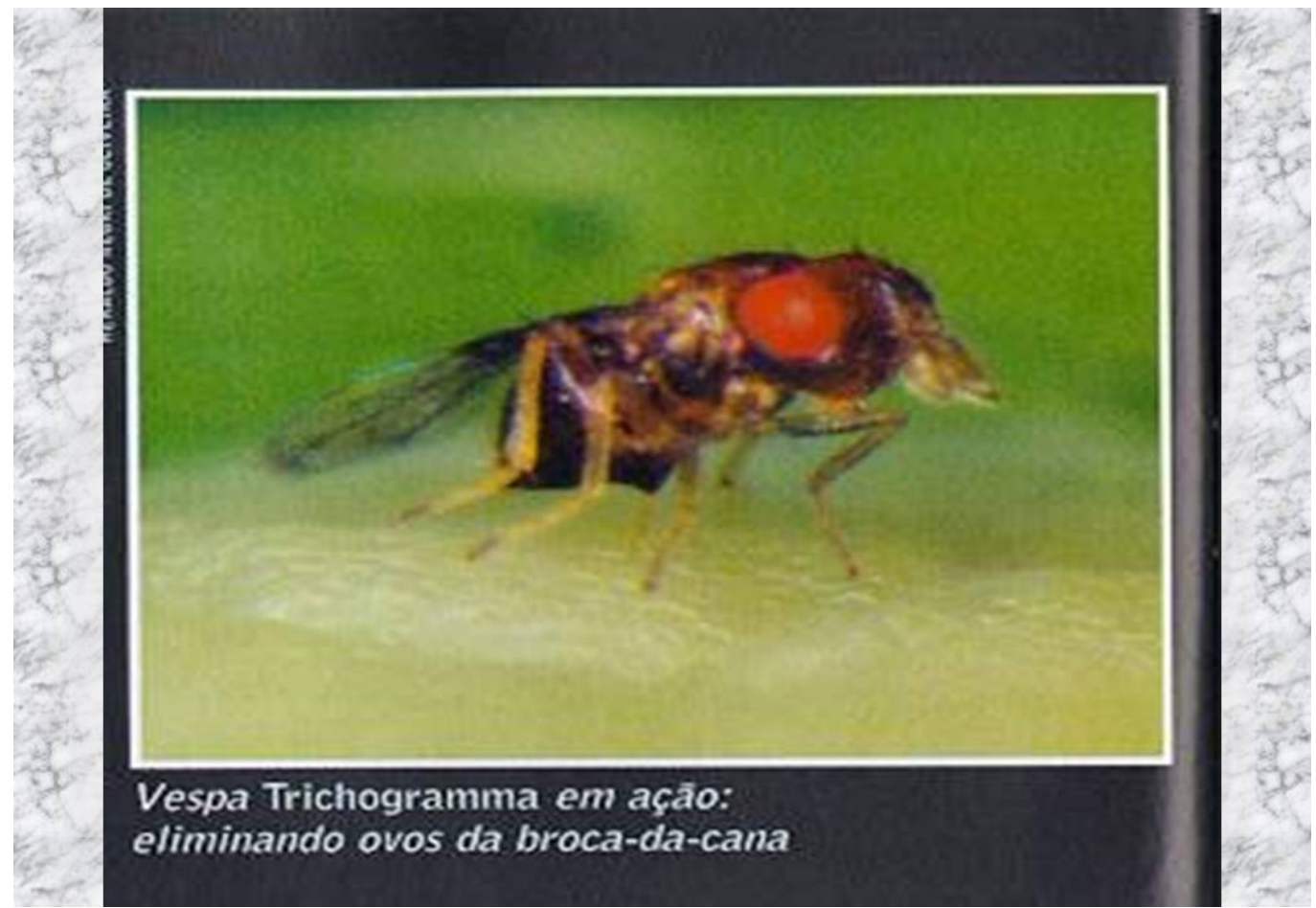

Caption 